\title{
Un falocentrismo sui géneris
}

\author{
A sui generis phallocentrism
}

\author{
Marcelo Frazzetto
}

\section{RESUMEN}

Las leyes Identidad de Género, Matrimonio Igualitario y Reproducción Asistida, promulgadas en nuestro país en los últimos años, causaron una profunda transformación en las políticas de identidad, visibilidad y respeto por las diferencias en la Argentina. El nuevo estatuto legal del matrimonio, que reconoce la posibilidad de sexualidades y familiaridades fuera de la biología y la heterosexualidad obligatoria, así como la libertad de elección del propio género, son una fuente de debates intelectuales a los cuales el psicoanálisis no ha escapado.

En los desarrollos recientes sobre sexualidad humana, resuena con insistencia la crítica al falocentrismo del psicoanálisis, como si éste fuera un privilegio del hombre. Siempre se acusó al psicoanálisis de falocéntrico, pero en todo caso más bien se lo ha pensado como penecéntrico.

¿Pero por qué el falo sería el mejor símbolo de lo sexual para los dos sexos? ¿Es por la visibilidad del pene? Lo que Lacan valoriza es que si el falo puede adoptar un valor simbólico lo es debido a la detumescencia y no a su imagen turgente.

\section{Abstract}

The Gender Identity, Equal Marriage and Assisted Reproduction Laws, promulgated in our country in recent years, caused a profound transformation in identity policies, visibility and respect for differences in Argentina. The new legal status of marriage, which recognizes the possibility of sexualities and familiarities outside biology and compulsory heterosexuality, as well as the freedom to choose one\&\#39;s own gender, are a source of intellectual debates to which psychoanalysis has not escaped.

In recent developments on human sexuality, the critique of the phallocentricism of psychoanalysis resounds insistently, as if it were a privilege of man. Psychoanalysis has always been accused of phallocentric, but in any case it has been thought more of as a peniscentric one.

But why would the phallus be the best symbol of the sexual for the both sexes? Is it because of the visibility of the penis? What Lacan values is that if the phallus can adopt a symbolic value it is due to detumescence and not to its turgid image. The authentic dismantling of phallocentrism is not to oppose identities that 
El auténtico desmantelamiento del falocentrismo no es oponerle identidades que lo reinscriban y se multipliquen en géneros, sino hacer comparecer la lógica del no-todo.

Palabras Clave

Falo - Castración - Sexo - Invariante No-todo re-inscribe it and are multiplied in genres, but to make the logic of non-everything appears.

\section{KEYWORDS}

Phallus - Castration - Sex - Invariant Non-whole 
Las leyes Identidad de Género, Matrimonio Igualitario y Reproducción Asistida, promulgadas en nuestro país en los últimos años, causaron una profunda transformación en las políticas de identidad, visibilidad y respeto por las diferencias en la Argentina. El nuevo estatuto legal del matrimonio, que reconoce la posibilidad de sexualidades y familiaridades fuera de la biología y la heterosexualidad obligatoria, así como la libertad de elección del propio género, son una fuente de debates intelectuales a los cuales el psicoanálisis no ha escapado.

Acusaciones de misoginia epistemológica, dominación masculina de la teorización sobre la mujer, pueden situarse como algunos de los términos del debate. En los desarrollos recientes sobre sexualidad humana, resuena con insistencia la crítica al falocentrismo del psicoanálisis, como si éste fuera un privilegio del hombre. Judith Butler, referente académico de las teorías de género, tanto en su libro El género en disputa. El feminismo y la subversión de la identidad (2007), como en Cuerpos que importan. Sobre los limites materiales y discursivos del sexo (2002), plantea una crítica al concepto de falo como significante privilegiado. Dice que es un efecto naturalizado de relaciones de poder que se basa en una reiterada práctica significante, abierta sin embargo a la significación, capaz por lo tanto de significar modos que exceden el lugar asignado en lo simbólico lacaniano. Propone así mismo cuestionar la necesidad de ese lugar. Beatriz Preciado por su parte, continúa esta línea de pensamiento y plantea que venimos de una cultura penecéntrica, teniendo en cuenta que hay una construcción de cierto lugar erógeno que se hace del pene, que no necesariamente tiene que ver con su natura- leza. Basa su investigación en el análisis fenomenológico de un elemento de tecnología sexual, el dildo (el consolador), al cual le atribuye funciones de construcción de subjetividad (Preciado, 2011).

Por otra parte, el progreso de la ciencia en la actualidad permite la separación de la procreación y el acto sexual, como así también la posibilidad de una maternidad sin hombres, lo cual crea la ilusión de que las mujeres pueden liberarse de la problemática fálica. Siempre se acusó al psicoanálisis de falocéntrico, pero en todo caso más bien se lo ha pensado como penecéntrico.

El lector light de la teoría freudiana ha equiparado, de manera rápida y equivocada, el órgano pene con el concepto falo, dándole el sentido peyorativo de teoría machista. Freud formó parte de una generación de hombres que se abrieron a escuchar a las mujeres, y no tuvo reparos en plantear el límite permeable de las identificaciones sexuales.

En primer término, es el mismo Freud quien precisa el sentido del concepto de falo cuando lo introduce en el contexto de la fase fálica. En el texto La organización genital infantil (Una interpolación a la teoría de la sexualidad), Freud dice: “... para ambos sexos, sólo desempeña un papel un genital, el masculino. Por tanto, no hay un primado genital, sino un primado del falo" (1976, p. 146). Si se trata de un solo órgano para ambos sexos entonces no se trata realmente de un órgano, ya que a nivel del cuerpo biológico cada uno tiene el suyo, por lo tanto se trata más bien de un símbolo.

Quizás constituye un problema de lectura de los textos freudianos el que muchas veces utilice la palabra pene para nombrar lo que es en realidad el falo. Si 
bien Freud nombra el penisneid (envidia de pene), que de hecho funciona en la histeria, también usa el término fallus (falo). Así todo, la historia de los conceptos en Freud se deben seguir hasta el final ya que justamente él mismo no deja de renovar sus interrogantes.

Falo es el representante sobre el que opera la castración y sobre el que se monta el desarrollo edípico. Por ser representante, hay que pensarlo en calidad de instancia simbólica e imaginaria y no como órgano. Como ese símbolo que ordenaba el mundo en castrado y no castrado tal como lo pensaba el célebre caso de Juanito.

¿Pero por qué el falo sería el mejor símbolo de lo sexual para los dos sexos? ¿Es por la visibilidad del pene? En relación a este tema hay algo que Lacan valoriza y que no es lo que normalmente se supone, y es lo siguiente: si el falo puede adoptar un valor simbólico lo es debido a la detumescencia. En el escrito de 1958, La significación del falo, Lacan expresa desde la primera línea la relación indisoluble entre el falo y la castración. Justamente porque la erección no se mantiene el pene puede tener un valor fálico. Es decir, se está en presencia de un falocentrismo muy particular ya que el falo indica cierto límite o lo que es lo mismo, simboliza la falta. En otro pasaje del mismo escrito, Lacan define el falo como velo, presentando el esquema siguiente: \$/cortina/objeto.... nada; dando a entender que siempre queda algo por satisfacer por medio del significante pero también un irreductible vinculado a él, noción que más adelante será conceptualizada como objeto $a$.

Lacan convoca a no quedarse sólo con la idea de falo como imagen turgente, a no tomar sólo en consideración el lugar que esta representación pudo haber tenido en ciertas culturas, incluso en diferentes culturas sin la menor conexión. El falo es un invariante de la humanidad, no es un invento de Freud, es un culto a la erectibilidad de lo humano, de ahí su relación con el pene en ese punto.

En los misterios griegos antiguos que se encuentran representados en los frescos de la Villa de Pompeya, tenían lugar determinados cultos fálicos (falos dibujados en los dinteles, los hornos de pan, tallados en las calzadas, incluso penes alados). La villa era en realidad una casa exclusiva para mujeres jóvenes que se iniciaban en los ritos dionisíacos. En dicho lugar, se puede ver una sala donde se muestra una serie de pinturas que representan el proceso de una joven que muda de aspecto a lo largo del recorrido. En una de las escenas centrales, la joven tiene el gesto de levantar un velo detrás del que se oculta un gran falo erecto. Mientras esto ocurre, un daimon femenino, una especie de demonio del pudor aparta el rostro y alza un flagellum, un látigo para aplicar el castigo ritual a la iniciada. En la siguiente escena, la ya iniciada baila en éxtasis.

Lacan señala al respecto que "así surge el fantasma de flagelación en su forma más directa e inmediatamente conectado con la revelación del falo" (1975, p. 356). Es decir que en los cultos antiguos, todo lo que se relaciona con el falo es objeto de amputaciones, de marcas de castración, como lo verifican algunos textos sobre los sacerdotes eunucos de la Gran Diosa Siria (Frazer, 1944).

Si el falo organiza el deseo humano, lo hace a partir de esta configuración que lo convierte en símbolo, más allá de lo imaginario, significante del deseo y castración, falta inscripta en el sujeto en el que incluso los objetos parciales solo adquieren valor 
a partir del hecho de que pueden faltar. Lacan introdujo la lingüística de Jakobson y Saussure para pensar el falo como significante, por ser el órgano apto para una función que el discurso precisa, algo que se puede poner y quitar.

Años más tarde en su último escrito, El Atolondradicho, vuelve sobre el tema: “Así, por el discurso analítico, un órgano se hace significante" (Lacan, 2012, p. 480). Vuelve a afirmar que el falo no designa el órgano pene con su fisiología, sino que apunta a la relación con el goce, no obstante no se desdice de lo planteado hasta aquí respecto del falo como significante. De esta forma da por terminada la controversia suscitada con Melanie Klein, para quien si las mujeres no tienen pene, los hombres por otro lado no disfrutarían el embarazo, rebajando la cuestión al nivel anatómico, cuando justamente lo anatómico no es determinante en este asunto.

Otro foco de debate tiene su origen en lo planteado por Freud respecto del Edipo femenino: la niña va a comprobar que su madre, al igual que ella, está desprovista de pene, al mismo tiempo que van a producirse transformaciones en su pulsión sexual. Es ahí donde define su famosa envidia de pene, madre de todas las críticas sobre el supuesto falocentrismo del psicoanálisis (1976, p. 270). Aquí radica la creencia de que para Freud las mujeres no serían más que seres disminuidos.

En el texto El sepultamiento del complejo de Edipo, Freud plantea que la suerte del varón no es más envidiable que la de la niña cuando tropieza con la diferencia de los sexos. Percibe la región genital de la niña pero se muestra poco interesado o directamente niega su percepción como manera de evitar o diferir la angustia de castración. La niña por su parte bascula menos, presentando la falta de pene como una herida (1976, p. 183). Freud indica que una mujer puede encontrar una compensación en la vanidad corporal, que le hace estimar en mayor medida sus atractivos y le permiten resarcirse de su supuesta inferioridad sexual inicial.

Hoy estos términos pueden parecer misóginos, sin embargo, no hay que olvidar que se trata de un contexto histórico diferente. Las mujeres de su época, no tan seguras de su posición, podían precaverse de manera un poco forzada de lo que experimentaban como una falla. Lo que el texto de Freud deja entrever es que el cuerpo en su totalidad accede al lugar donde se encontró la falta fálica. Aunque se la conciba como no teniéndolo, puede decirse que ella lo es.

Ser el falo no es una expresión freudiana, pero hace surgir una transformación al binario tener o no el falo. Para Lacan, la falta fálica de la mujer se convierte en un beneficio de ser el falo, es decir, ser lo que le falta al Otro, y este ser el falo designa a la mujer en tanto es llamada al lugar de objeto. Según Soler: "En el amor, por la gracia del deseo del partenaire, la falta se convierte en un efecto de ser casi compensatorio: ella llega a ser lo que no tiene. La falta femenina entonces ya aparece como positivizada" (2015, p. 42).

Es necesario subrayar un planteo implícito en esta argumentación: ser el falo, o sea, el representante de lo que le falta al hombre, ser el objeto causa de su deseo, ser el síntoma en que se fija su goce, definen a la mujer como relativa al hombre (pero es algo que también le pasa a la hombre respecto de la mujer, es decir, ser tomado como objeto) y no dicen nada de su ser en sí sino de su ser para el Otro. Por lo tanto, esta posición concierne más a su 
semblante que a su ser propio, que queda forcluido del discurso.

Cuando Lacan plantea el falo como significante del deseo del Otro en el contexto del escrito La significación del falo (1975), su argumento vuelve a quebrar el binarismo de complementación heterosexual que ya había quebrado Freud. Cabe recordar que para Freud hay un solo genital en lo inconsciente, el falo, por lo tanto, la única posibilidad binaria que se establecería con el falo es la castración. Significante del deseo del Otro implica que se trata de una posición subjetiva, es decir, el falo permite la instalación de una determinada posición como sujeto del inconsciente, la cual a su vez posibilita la identificación con el tipo ideal del sexo, más allá de cómo se denomine ese sexo: hombre, mujer, hetero, homo, trans. Por lo tanto, el inconsciente carece de sexo, pero se le abre el camino en cambio, para identificarse al tipo ideal, lo cual no significa que la posición inconsciente sea sexuada. Para Lacan los sexos no son dos polos que se rigen por lo que se llama en lógica negación complementaria: definir un atributo, englobar a los que lo poseen y lo que entra en uno no entra en el otro. Ninguna predicación da cuenta del ser, nada de lo que pueda predicarse de un objeto lo exhaustiva, por lo tanto, no hay características sexológicas o sociológicas que prediquen comportamientos del orden de lo universal.

Por supuesto, el debate no termina aquí ya que Lacan le da a la mujer un valor de estructura, cuestión no siempre valorada desde la posición feminista, aunque para abordar dicha cuestión es necesario transitar nuevos aportes a la formalización de la diferencia sexual. Quienes se dicen mujeres, no importa su anatomía, tienen la posibilidad estructural de relacionarse directamente con el significante de la falta del Otro sin intermediación del falo, por lo tanto, una relación más amplia con el inconsciente, con el deseo, con lo real. El Edipo femenino según Lacan, y aquí subyace la diferencia con el planteo freudiano, no tiene porqué terminar en la envidia de pene subsanada con hijitos.

Recordemos que para el Edipo femenino Freud pensó tres orientaciones: masculinidad, femineidad y renuncia. La femineidad, también llamada de evolución normal, deriva de su ser castrada, cuya falta fálica la incita a dirigirse hacia el amor de un hombre: primero el padre, heredero de una transferencia de amor que anteriormente se dirigió a la madre, y después a un hombre, de quien espera el sustituto fálico en forma de niño. Freud le da a la feminidad una versión fálica, lo cual hace que su planteo se quede corto. Lacan en cambio, piensa la femineidad como más allá de la versión fálica. Según las fórmulas de la sexuación trabajadas en El Seminario 20: Aún (1981), las mujeres participan de una doble dirección ya que se dirigen a $\Phi$ y a $\mathbf{S}(\mathbb{A})$. Es decir, la mujer tiene posibilidad de un goce que excede el goce fálico, que en el álgebra lacaniana se escribe $S(\mathbb{A})$, significante del Otro barrado, el agujero. Es un goce del que nada puede decirse pero que sin embargo hace decir (Cancina, 1990). No está mediado por el significante fálico sino por una creación significante propia, un significante nuevo que inventa quien está en posición femenina. Por eso dicha posición tiene una relación más directa y sencilla con $\mathrm{S}(\mathbb{A})$ con ese punto vacío; tiene la posibilidad estructural de relacionarse con la falta del Otro, o sea, con el inconsciente, por ende, con lo real.

La lógica de la sexuación rompe el 
sentido del género hombre-mujer, heterosexual-homosexual. Allí el llamado falocentrismo no es una voluntad de poder impuesta por un sistema estratégico tal como es planteado desde las teorías de género, sino uno de los destinos posibles del símbolo falo, es decir, un modo neurótico que imagina el goce del falo como el único posible (Alemán, 2015, p. 37).

En todo caso, si una sociedad deposita el poder falóforo, la portación del falo, no de pene, sólo en los varones, entonces se está en presencia de una sociedad patriarcal. Pero si la sociedad fuera no patriarcal, también el falo cumpliría así mismo una función invariante. Falo y función paterna no son para el psicoanálisis emanaciones del discurso patriarcal.

Desde el paleolítico el hombre que habla erige homenajes al falo: dólmenes, menhires, túmulos, etc., tanto como símbolo de la erectibilidad de lo humano, fertilidad o función apotropaica. El falo nunca fue confundido con el pene sino que tenía una función sagrada (tal como se constata en la antigüedad griega y en las excavaciones de Pompeya), que hacía de protección de la entrada de las casas humanas. Para el humano mortal, signo de la interdicción del incesto y para los inmortales, el órgano copulatorio con el Otro que sólo a los dioses del goce estaba permitido (Amigo, 2017).

A través del tiempo fue variando el Uno falóforo que era portador de ese poder humanizante e interdictor. Primero en el endiosamiento de los muertos, luego en los dioses de la naturaleza y posteriormente en los dioses olímpicos (de Coulanges, 2000). Fue recién con la universalización del judaísmo en su versión cristiana, que el Uno falóforo pasó al dios monoteísta de la ley.
La función del padre como falóforo no es una figura natural sino cultural, aquel que transmite la norma de la cultura. El falo es el símbolo princeps de la prohibición del incesto en Nombre del Padre, lo cual no significa un desmedro para la mujer sino todo lo contrario. Es la mujer quien transmite ese nombre y es quien funciona como guardiana de lo real indominable al ciento por ciento por el significante Nombre del Padre.

A partir de Descartes ese Uno falóforo es depositado en la figura laica del padre. Desde ese momento padre designa aquel en cuyo nombre se inscribe el agujero inabordable de la cosa incestuosa. Por cuya pérdida nace el deseo (un invariante) y el sujeto es impulsado en su rumbo por el objeto perdido (otro invariante). Hoy podríamos decir, independiente de la anatomía o la sexualidad de quien inscribe dicho agujero.

Las épocas pueden cambiar pero el falo y la prohibición de la cosa incestuosa serán invariantes a respetar. Hoy parte de nuestra vida sigue rigiéndose por el discurso maître, el Uno que asume el decir paterno, la dupla falo/castración, el deseo que pone tope al goce todo y el sujeto dividido entre significantes con su deseo causado por el objeto.

La invariancia está en que, para el psicoanálisis, falo es la letra del agujero inconsciente y el primer regulador del agujero central del Otro real. Es decir, habrá en el sujeto un lugar de falta marcado por una letra, $\Phi$ (falo simbólico en la simbología lacaniana) para que la neurosis pueda constituirse. Siempre que esté el falo en la estructura se puede estar seguro que esa estructura tiene un agujero, un cero funcional, tal como Lacan lo siguiendo a Frege. Pero independiente que se la nombre 
$\Phi, \mathrm{X}$, o como se quiera, lo importante es que habrá o no un lugar de falta en el que ese sujeto pueda alojarse.

El auténtico desmantelamiento del falocentrismo no es oponerle identidades que lo reinscriban y se multipliquen en géneros, sino hacer comparecer la lógica del no-todo. Esta lógica de incompletud propia del inconsciente hace que se vuelva imposible toda bipolaridad, lo cual trae consecuencias sobre el goce de cada sujeto. Hay dos maneras de fallar lo simbólico, expresa Lacan, y el sexo es el nombre de esa falla (1981, p. 72). A la grieta del universo simbólico (grieta del lenguaje devenido simbólico como resultado de la primera identificación al falo) se le sobreimprime la falla sexual (dos maneras de fallar: masculina y femenina). Dos fallas que implican dos maneras de gozar, que no son simétricas; cada una definida por una negación de la función fálica.

\section{REFERENCIAS BibLIOGRÁficAS}

Alemán, J. (2015). Lacan-Foucault: el "construccionismo". Psicoanálisis y el Hospital. Publicación semestral de practicantes en instituciones hospitalarias. $\mathrm{N}^{\mathrm{o}} 47,27-37$.

Amigo, S. (2017). "Retorno a Lacan-Vigencia de los conceptos fundamentales (Psicoanálisis)”. Diario literario digital.

Butler, J. (2007). “El género en disputa. El feminismo y la subversión de la identidad”. Buenos Aires: Paidós. (2002). "Cuerpos que importan. Sobre los límites materiales y discursivos del sexo". Buenos aires: Paidós.

Cancina, P. (1990). "Escritura y femineidad: Ensayo sobre la obra de Marguerite Duras.” Buenos Aires: Nueva Visión.

Frazer, J. (1944). "La rama dorada: Magia y religión”. México: Fondo de Cultura Económica.

Freud, S. (1976). "La organización genital infantil”. O. C. Tomo XIX. Buenos Aires: Amorrortu.

(1976). "El sepultamiento del complejo de Edipo”. O. C. Tomo XIX. Buenos Aires: Amorrortu.

(1976). "Algunas consecuencias

psíquicas de la diferencia anatómica entre los sexos”. O. C. Tomo XIX. Buenos Aires: Amorrortu.

LACAN, J. (1975). "La significación del falo". Escritos II. Buenos Aires: Siglo Veintiuno. (1981). El Seminario 20: Aún. Buenos Aires: Paidós. (2012). "El Atolondradicho". Otros Escritos. Buenos Aires: Paidós. 
Preciado, B. (2011). "Manifiesto contrasexual”. Barcelona: Anagrama.

Soler, C. (2015). Lo que Lacan dijo de las mujeres: Estudio de psicoanálisis. Buenos Aires: Paidós.

Como CITAR eSte ARTículo:

Frazzetto, M (2019). Un falocentrismo sui generis en Revista psicoanálisis en la Universidad $N^{\circ} 3$. Rosario, Argentina. UNR editora

Marcelo A. Frazzetto.

Psicoanalista. Especialista en Psicología Clínica, Institucional y Comunitaria. Docente e investigador del Programa Nacional de Incentivos. Prof Adjunto de la cátedra Psicología, Facultad de Psicología de la UNR. Ex Jefe de Residentes de la Dirección de Salud Mental de la Municipalidad de Rosario. 